\title{
Researchers reduce severity of sleep apnoea by at least 30\%
}

New research published in The Journal of Physiology shows that researchers have successfully repurposed two existing medications to reduce the severity of sleep apnoea in people by at least $30 \% .{ }^{1}$

Affecting around 1.5 million adults in the UK, sleep apnoea is a condition where the upper airway from the back of the nose to the throat closes repeatedly during sleep, restricting oxygen intake and causing people to wake as often as 100 times or more per hour. ${ }^{1}$

Those with untreated sleep apnoea are more likely to develop cardiovascular disease, dementia and depression, and are two to four times more likely to crash a car than the general population. ${ }^{2}$ Despite almost 30 years of research, there are no approved drug therapies to treat the condition.

Professor Danny Eckert, Principal Research Scientist at NeuRA and Professor and Director of Adelaide Institute for Sleep Health at Flinders University, has brought scientists one step closer by repurposing two existing medications to test their efficacy in people with sleep apnoea.

Previous research showed two classes of medication, reboxetine and butylbromide, were able to keep muscles active during sleep in people without sleep apnoea and assist their ability to breathe. By repurposing the medications, researchers used a multitude of recording instruments to measure whether reboxetine and butylbromide could successfully target the main causes of sleep apnoea. This included balancing the electrical activity of muscles around the airway, preventing the throat from collapsing during sleep and improving the regulation of carbon dioxide and breathing during sleep.

Results from the study showed these medications did in fact increase the muscle activity around participants' airways, with the drugs reducing the severity of participants' sleep apnoea by up to one-third.

Almost everyone studied had some improvement in sleep apnoea. Participants' oxygen intake improved and their number of breathing stoppages reduced by at least a third.

These new findings allow researchers to further refine these types of medications so that they have even greater benefit than that which has currently been found.

Professor Eckert said: 'We were thrilled because the current treatment options for people with sleep apnoea are limited and can be a painful journey for many. Next, we will look at the effects of these and similar medications over the longer term. We will assess whether we can harness the benefits of one drug without needing to use them both.

'Equally, we will test whether these treatments can be combined with other existing medications to see if we can improve their efficacy even more.'

Until now, the main therapy for sleep apnoea involves wearing a mask to bed, or continuous positive airway pressure (CPAP) therapy, which benefits millions. However, many people find it uncomfortable and half the people that try it find it hard to tolerate. Also, the efficacy of second-line therapies, such as mouthguards fitted by dentists, can be unpredictable and expensive.

\section{References}

1. Lim R, Messineo L, Grunstein R R, Carberry J C, Eckert $D$ J. The noradrenergic agent reboxetine plus antimuscarinic hyoscine butylbromide reduces sleep apnoea severity: A double-blind, placebo-controlled, randomised crossover trial. J Physiol 2021; doi: 10.1113/JP281912

2. Teran-Santos J, Jimenez-Gomez A, Cordero-Guevara J. The association between sleep apnea and the risk of traffic accidents. Cooperative Group BurgosSantander. N Engl J Med 1999; 340: 847-851.

\section{Unethical migrant dental checks are a 'retrograde step'}

The British Dental Association (BDA) has urged Home Secretary Priti Patel to think again on plans to introduce dental checks to establish the age of Channel migrants.

According to reports, a new independent nationwide panel will use dental records and other 'scientific evidence' to verify the age of asylum seekers.

The BDA has vigorously opposed the use of dental $\mathrm{x}$-rays to determine whether asylum seekers have reached the age of 18 , stressing they are an inaccurate method for assessing age.

The BDA also believes that it is inappropriate and unethical to take radiographs of people when there is no health benefit for them. Radiographs taken for a clinically justified reason must not be used for another purpose without the patient's informed consent, and must be carried out without coercion and in full knowledge of how the radiograph will be used and by whom.

The new Nationality and Borders Bill, tabled on 6 July, will give the Home Secretary the powers to introduce methods of assessing age via regulation. ${ }^{1}$

This new position runs counter to statements adopted by the Home Office in 2016, when the Department rejected similar calls from backbencher David Davies MP.

BDA Chair Eddie Crouch said: 'This is a retrograde step from Priti Patel. In 2016 the Home Office ruled out dental checks for migrants, which we considered inaccurate,

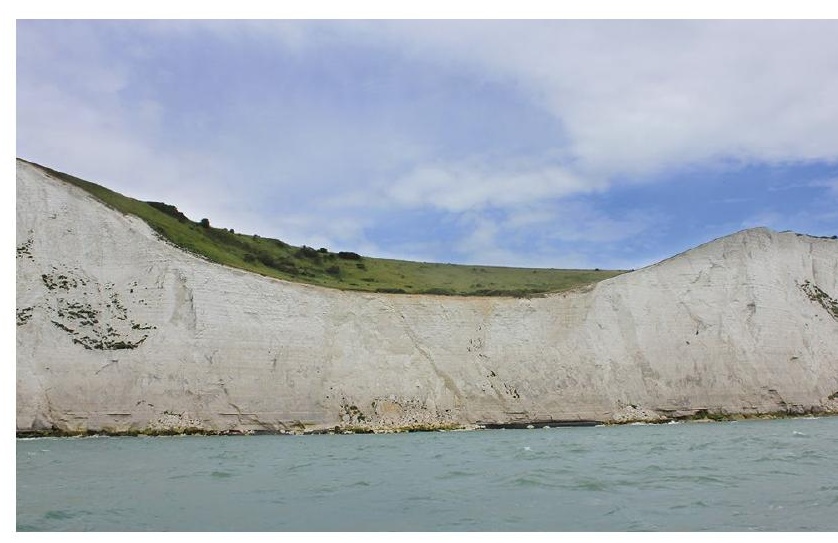

inappropriate and unethical. In 2021, the science and ethics have not changed'.

\section{Reference}

1. UK Parliament. Nationality and Borders Bill. S 58 Age assessments. Last updated 9 July 2021. Available at: https:// bills.parliament.uk/bills/3023 (accessed July 2021). 